\title{
Short communication: Characterization of Staphylococcus aureus isolated along the raw milk cheese production process in artisan dairies in Italy
}

\author{
S. Johler, ${ }^{* 1}$ G. Macori, $\dagger^{1,2}$ A. Bellio, $\dagger$ P. L. Acutis, $\dagger$ S. Gallina, $\dagger$ and L. Decastelli† \\ *Institute for Food Safety and Hygiene, Vetsuisse Faculty University of Zurich, 8057 Zurich, Switzerland \\ †Istituto Zooprofilattico Sperimentale del Piemonte, Liguria e Valle d'Aosta, 10154 Torino, Italy
}

\begin{abstract}
Staphylococcus aureus is a common cause of foodborne intoxications. Several staphylococcal food poisoning outbreaks have been linked to consumption of raw milk cheeses and artisanal cheese production. However, information on Staph. aureus isolated from artisanal raw milk cheeses and small-scale dairy production environments is very limited. Therefore, we aimed to characterize Staph. aureus isolated along the artisanal raw milk production chain by determining (1) the population structure, and (2) the presence/absence of enterotoxin genes, mecA/C, and pvl. We collected 276 samples from different production stages (raw milk, whey, curd, brine, drying worktops, and cheese) at 36 artisan dairies in Italy. A total of 102 samples from 25 dairies tested positive for Staph. aureus, with $80 \%$ positive samples among the tested artisan cheeses. All isolates were further characterized by spa typing and PCR screening for staphylococcal enterotoxin genes, the mecA/mecC genes characteristic for methicillinresistant Staph. aureus, and the pvl gene encoding Panton-Valentine leukocidin. The 102 isolates represented 15 different spa types and were assigned to 32 different Staph. aureus strains. The spa type most frequently detected was t2953 (30\%), which is associated with genotype B strains causing high within-herd levels of bovine mastitis. In addition, 3 novel spa types (t13269, t13277, and t13278) were identified. Although none of the strains harbored mecA/mecC or pvl, $55 \%$ of the isolates exhibited at least one enterotoxin gene. Many strains were present in samples from multiple dairies from different regions and years, highlighting the spread of Staph. aureus in small-scale cheese production plants. Our findings demonstrate that enterotoxigenic Staph. aureus and in particular t2953 (genotype B)
\end{abstract}

Received September 11, 2017.

Accepted December 9, 2017.

${ }^{1}$ Both authors contributed equally.

${ }^{2}$ Corresponding author: guerrino.macori@gmail.com isolates commonly occur in artisanal dairies and raw milk cheeses in Italy. It is particularly alarming that $80 \%$ of the artisan cheeses sampled in our study were positive for Staph. aureus. These findings stress the need for effective measures preventing staphylococcal food poisoning by limiting Staph. aureus growth and enterotoxin formation along the production chain and in the final product.

Key words: spa typing, enterotoxin, staphylococcal food poisoning, methicillin-resistant Staphylococcus aureus

\section{Short Communication}

Staphylococcus aureus is frequently isolated from raw milk intended for cheese production, dairy processing equipment, and environments, as well as food handlers. Its presence in raw milk represents a source for introduction of Staph. aureus into the dairy product supply chain (D'amico and Donnelly, 2011). Ingestion of staphylococcal enterotoxins produced by Staph. aureus in food can result in staphylococcal food poisoning, and several outbreaks linked to consumption of raw milk cheeses and artisanal cheeses have been reported (Johler et al., 2015a,b). Enterotoxigenic strains originating from small-scale cheese productions may also carry a wide variety of important resistance and virulence determinants including mecA/mecC, conferring methicillin resistance or $p v l$ coding for the $\beta$-pore-forming toxin Panton-Valentine leukocidin (Herrera et al., 2016).

Information on Staph. aureus from artisanal raw milk cheeses and dairy production environments is scarce. Although a large amount of the cow milk produced in Italy is used in the manufacture of typical raw milk cheeses, few data on the occurrence and genomic characteristics of Staph. aureus from these sources are available. A previous study screening raw milk and raw milk cheeses in the Turin area reported that $39 \%$ of samples were positive for Staph. aureus and that $21 \%$ of the isolates carried enterotoxin genes (Bianchi et al., 2014). Another study performed in the Apulia and Basilicata region detected methicillin-resistant Staph. aureus in 
$2.5 \%$ of bulk tank milk samples tested (Parisi et al., 2016).

Phenotypic or genotypic typing methods can be used to discriminate different Staph. aureus isolates, for host attribution or to determine the relatedness of different isolates. Sequencing and analysis of the polymorphic $\mathrm{X}$ region of the protein A gene (spa typing) was shown to yield excellent discriminatory power (Koreen et al., 2004).

The aim of this study was to characterize isolates of Staph. aureus from raw milk cheese productions of small-scale artisan cheese manufactures in Italy by determining spa types and the presence/absence of enterotoxin genes, mecA $/ C$, and $p v l$.

All isolates used in this study were collected in Italy between 2010 and 2012. We sampled and re-sampled 36 dairies producing artisanal raw milk cheeses from bovine milk in Piedmont and Aosta Valley. Samples were taken from raw milk $(\mathrm{n}=36)$, whey $(\mathrm{n}=36)$, curd $(\mathrm{n}=36)$, brine $(\mathrm{n}=36)$, drying worktops ( $\mathrm{n}$ $=36)$, and cheese $(\mathrm{n}=96)$. Information on sample type, dairy, and year is included in Supplemental Table S1 (https://doi.org/10.3168/jds.2017-13815). Food samples were processed according to the ISO 6888-2 (ISO, 1999) method for the detection and enumeration of coagulase-positive staphylococci. For each sample, 5 colonies displaying a phenotype characteristic for coagulase-positive staphylococci were streaked on blood agar plates and identified as Staph. aureus using the VITEK system GP card (bioMérieux, Marcy l'Etoile,
France). Environmental swab samples were placed in 10 $\mathrm{mL}$ of Mueller-Hinton broth (Oxoid, Basingstoke, UK) supplemented with $6.5 \% \mathrm{NaCl}$ (Sigma-Aldrich, Arklow, Ireland), vortexed, and incubated for $24 \mathrm{~h}$ at $37^{\circ} \mathrm{C}$. After incubation, an aliquot of $100 \mu \mathrm{L}$ was pour plated in rabbit plasma fibrinogen Baird Parker agar plates (Oxoid) and incubated at $37^{\circ} \mathrm{C}$. Species confirmation for colonies displaying a Staph. aureus characteristic phenotype after 24 or $48 \mathrm{~h}$ was performed by using a VITEK system GP card (bioMérieux).

Genomic DNA was extracted from Staph. aureus strains using InstaGene Matrix (Bio-Rad, Milan, Italy). Each colony was suspended in $100 \mu \mathrm{L}$ of matrix buffer, incubated at $56^{\circ} \mathrm{C}$ for $60 \mathrm{~min}$, followed by incubation at $95^{\circ} \mathrm{C}$ for $45 \mathrm{~min}$. The suspensions were centrifuged at $20,000 \times g$ for 5 min and supernatants were used for PCR screening of all isolates for enterotoxin genes, pvl, $m e c A$, and $m e c C$. Enterotoxin genes were detected using 2 multiplex PCR assays (see Table 1) according to the protocols of the European Union Reference Laboratory for Coagulase-Positive Staphylococci (Kérouanton et al., 2007). The following reference strains were included as positive controls: FRIS6 (sea, seb), FRI137 (seg, seh, sei), FRI326 (see), FRI361 (sec, sed, ser), and HMPL280 (seg, sei, selj, selp). The PCR screening for $m e c A / m e c C$ and $p v l$ was performed as previously described (Stegger et al., 2012). We determined spa types as previously described (Johler et al., 2011) and depicted results by constructing a minimum spanning tree (BioNumerics software ver. 7.6, Applied Maths Inc., Austin, TX). Iso-

Table 1. Primers used for the detection of Staphylococcus aureus enterotoxin genes by a multiplex PCR approach ${ }^{1}$

\begin{tabular}{|c|c|c|c|c|}
\hline Gene & Primer & Primer sequence $\left(5^{\prime}-3^{\prime}\right)$ & $\begin{array}{l}\text { Product } \\
\text { size }(b p)\end{array}$ & Reference \\
\hline sea & $\begin{array}{l}\text { GSEAR-1 } \\
\text { GSEAR-2 }\end{array}$ & $\begin{array}{l}\text { GGT TAT CAA TGT GCG GGT GG } \\
\text { CGG CAC TTT TTT CTC TTC GG }\end{array}$ & 102 & Mehrotra et al., 2000 \\
\hline$s e b$ & $\begin{array}{l}\text { GSEBR-1 } \\
\text { GSEBR-2 }\end{array}$ & $\begin{array}{l}\text { GTA TGG TGG TGT AAC TGA GC } \\
\text { CCA AAT AGT GAC GAG TTA GG }\end{array}$ & 164 & Mehrotra et al., 2000 \\
\hline$s e c$ & $\begin{array}{l}\text { GSECR-1 } \\
\text { GSECR-2 }\end{array}$ & $\begin{array}{l}\text { AGA TGA AGT AGT TGA TGT GTA TGG } \\
\text { CAC ACT TTT AGA ATC AAC CG }\end{array}$ & 451 & Mehrotra et al., 2000 \\
\hline sed & $\begin{array}{l}\text { GSEDR-1 } \\
\text { GSEDR-2 }\end{array}$ & $\begin{array}{l}\text { CCA ATA ATA GGA GAA AAT AAA AG } \\
\text { ATT GGT ATT TTT TTT CGT TC }\end{array}$ & 278 & Mehrotra et al., 2000 \\
\hline see & $\begin{array}{l}\text { SA-U } \\
\text { SA-E rev }\end{array}$ & $\begin{array}{l}\text { TGT ATG TAT GGA GGT GTA AC } \\
\text { GCC AAA GCT GTC TGA G }\end{array}$ & 213 & Sharma et al., 2000 \\
\hline ser & $\begin{array}{l}\text { SER } 1 \\
\text { SER } 2\end{array}$ & $\begin{array}{l}\text { AGA TGT GTT TGG AAT ACC CTA T } \\
\text { CTA TCA GCT GTG GAG TGC AT }\end{array}$ & 123 & Chiang et al., 2008 \\
\hline $\operatorname{seg}$ & $\begin{array}{l}\text { SEG-F } \\
\text { SEG-R }\end{array}$ & $\begin{array}{l}\text { GTT AGA GGA GGT TTT ATG } \\
\text { TTC CTT CAA CAG GTG GAG A }\end{array}$ & 198 & Bania et al., 2006 \\
\hline seh & $\begin{array}{l}\text { SEH-F } \\
\text { SEH-R }\end{array}$ & $\begin{array}{l}\text { CAA CTG CTG ATT TAG CTC AG } \\
\text { CCC AAA CAT TAG CAC CA }\end{array}$ & 173 & Bania et al., 2006 \\
\hline$s e i$ & $\begin{array}{l}\text { SEI-F } \\
\text { SEI-R }\end{array}$ & $\begin{array}{l}\text { GGC CAC TTT ATC AGG ACA } \\
\text { AAC TTA CAG GCA GTC CA }\end{array}$ & 328 & Bania et al., 2006 \\
\hline selj & $\begin{array}{l}\text { SEJ-F } \\
\text { SEJ-R }\end{array}$ & $\begin{array}{l}\text { GTT CTG GTG GTA AAC CA } \\
\text { GCG GAA CAA CAG TTC TGA }\end{array}$ & 131 & Bania et al., 2006 \\
\hline $\operatorname{selp}$ & $\begin{array}{l}\text { SEP-F } \\
\text { SEP-R }\end{array}$ & $\begin{array}{l}\text { TCA AAA GAC ACC GCC AA } \\
\text { ATT GTC CTT GAG CAC CA }\end{array}$ & 396 & Bania et al., 2006 \\
\hline
\end{tabular}

\footnotetext{
${ }^{1}$ Annealing temperatures used were $55^{\circ} \mathrm{C}$ for the first multiplex PCR (sea-see, ser), and $52^{\circ} \mathrm{C}$ for the second multiplex PCR $($ seg-selj, selp).
} 
lates with identical spa types, as well as virulence and resistance gene profiles, were considered to represent the same strain.

Out of 276 samples from 36 dairies, 102 samples from 25 dairies tested positive for Staph. aureus. Positive samples were detected along the whole production chain (Table 2), with $19 \%$ positive raw milk samples, $6 \%$ positive whey samples, $14 \%$ positive curd samples, $11 \%$ positive brine samples, and $19 \%$ positive samples from drying worktops. Eighty percent of the samples originating from the artisan raw milk cheese itself were positive for Staph. aureus. This is consistent with a previous study (Johler et al., 2016) showing that the organism can enter the artisanal cheese-making process at different stages of the manual production, with colonized cheese makers representing a likely source of Staph. aureus. A total of $55 \%$ of all isolates and $56 \%$ of the cheese isolates exhibited at least one gene encoding SEA, SEB, SED, SElJ, SEG, SEI, or SER. Most enterotoxigenic isolates harbored both classical (sea-see) and new staphylococcal enterotoxin genes (ser, seg, seh, sei, selj, selp). Consistent with the findings of Blaiotta et al. (2006), seg and sei always coexisted and were never detected independently of the other gene. A previous study screening Italian raw milk and raw milk cheeses reported that $39 \%$ of samples were positive for Staph. aureus, with $21 \%$ of the isolates carrying enterotoxin genes (Bianchi et al., 2014). No Panton-Valentine leukocidin or methicillin resistance genes were detected, consistent with previous studies demonstrating low prevalence of these genes among Staph. aureus isolated from dairy products in Italy (Spanu et al., 2012; Mancini et al., 2015; Parisi et al., 2016). A complete list of all Staph. aureus isolates detailing the dairy, sample type, year of isolation, spa type, and repeat sequence, as well as the results of the PCR screening for enterotoxin and virulence $(\operatorname{mec} A / C, p v l)$ genes, is provided in Supplemental Table S1 (https://doi.org/10.3168/jds .2017-13815).

The 102 isolates were assigned to 15 different spa types. The most common spa types were t2953 ( $\mathrm{n}=$ $30)$, t524 $(\mathrm{n}=14)$, and t267 $(\mathrm{n}=11)$. In a previous study, t2953 was one of several spa types associated with Staph. aureus strains of genotype B, which are exclusively linked to high within-herd prevalence of bovine mastitis (Graber et al., 2009; Boss et al., 2016). Staphylococcus aureus of genotype B were reported to represent a major contaminant in raw milk cheeses in Switzerland and were identified as the causative agent in outbreaks of staphylococcal food poisoning (Hummerjohann et al., 2014; Johler et al., 2015b). Staphylococcus aureus of spa type t524 have been commonly detected in bovine mastitis milk in various countries (Hasman et al., 2010; Johler et al., 2011; Sakwinska et al., 2011). Staphylococcus aureus t267 strains have been isolated from mastitis milk in cattle and sheep (Johler et al., 2011; Merz et al., 2016), from poultry (Krupa et al., 2014), and from samples of human patients suffering from bloodstream infections (Nulens et al., 2008). In addition, the first reported vancomycinresistant Staph. aureus detected in bovine milk, which was isolated in India, belonged to t267 (Bhattacharyya et al., 2016). We constructed a minimum spanning tree to depict the frequency and genetic relatedness among spa types detected in this study (Figure 1). Three novel spa types were identified: t13269 $(\mathrm{n}=3)$, t13277 (n $=5)$, and $113278(\mathrm{n}=2)$. Each of these spa types was detected in samples from 2 different dairies. The spa types t13278 (repeat succession: 11-12-12-22-25) and t13269 (repeat succession: 11-12-12-22-25-25) are closely related and differ only by one spa repeat. A comprehensive list of all spa types detected, as well as associated dairies and virulence and resistance genes, is included in Table 3.

The 102 isolates collected in this study represented 32 strains, 10 of which were isolated from more than one dairy. The enterotoxigenic genotype B strain S22 (t2953; sed/selj/ser) was isolated from 21 samples originating from raw milk, brine, a drying worktop, and cheese samples collected over a time span of $3 \mathrm{yr}$ from 10 different dairies. In approximately two-thirds of the dairies (69\%), at least one Staph. aureus strain was detected. Although $47 \%$ harbored only one strain, $22 \%$ of the dairies were linked to more than one Staph. aureus

Table 2. Staphylococcus aureus isolates detected in 25 out of 36 tested artisan dairies along the cheese production process

\begin{tabular}{lccc}
\hline Production stage & $\begin{array}{c}\text { No. of samples } \\
\text { taken }\end{array}$ & $\begin{array}{c}\text { No. of isolates } \\
\text { detected }\end{array}$ & $\begin{array}{c}\text { Prevalence } \\
(\%)\end{array}$ \\
\hline Raw milk & 36 & 7 & 19 \\
Whey & 36 & 2 & 6 \\
Curd & 36 & 5 & 14 \\
Brine & 36 & 4 & 11 \\
Drying worktops & 36 & 7 & 19 \\
Raw milk cheese & 96 & 77 & 80 \\
Total & 276 & 102 & 37 \\
\hline
\end{tabular}




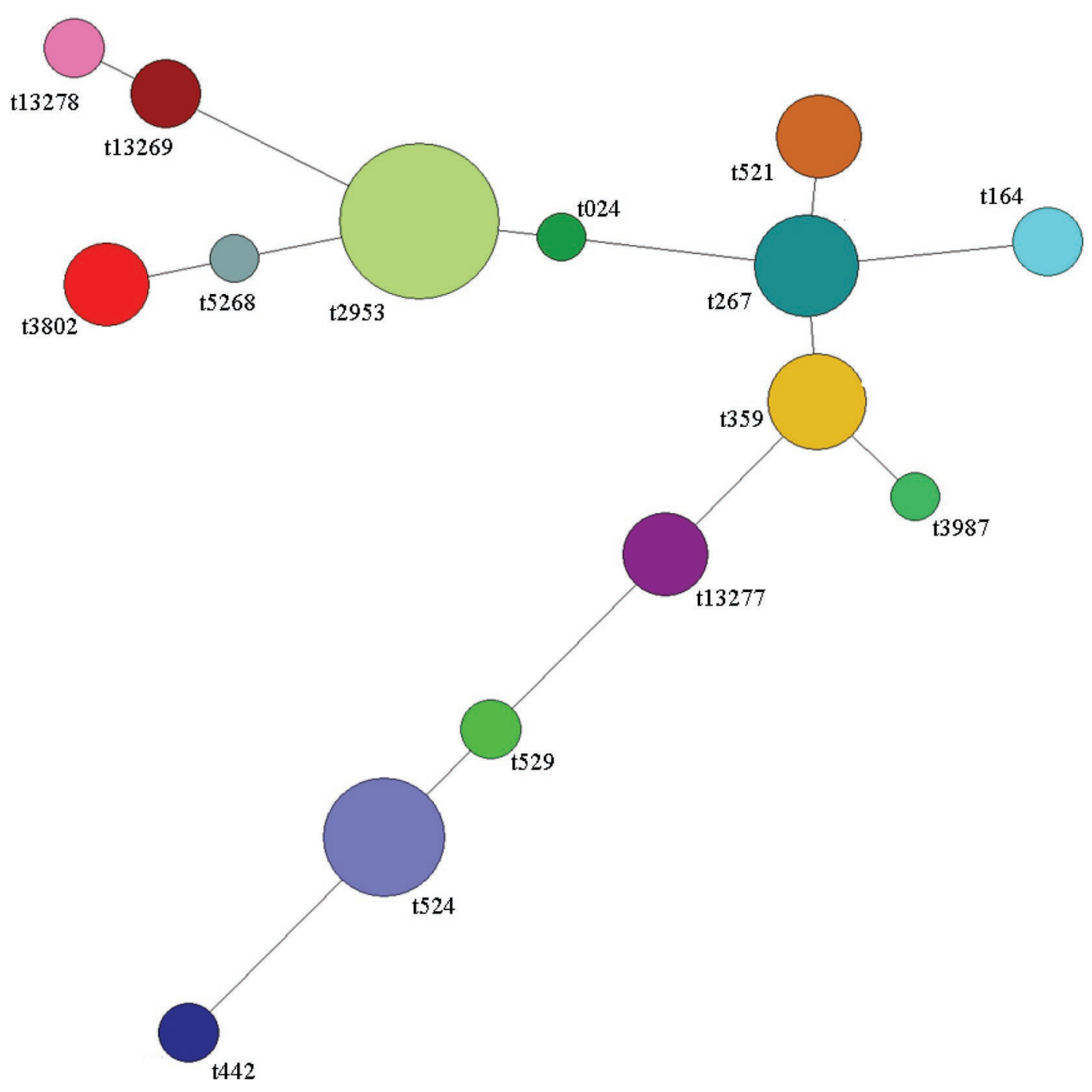

Figure 1. Minimum spanning tree visualizing the spa typing results. Each spa type is depicted by a single node, with the size of the node representing the number of isolates associated with this spa type. Color version available online.

strain. The most extreme case was dairy D1, which harbored 15 different Staph. aureus strains identified in samples from brine, curd, drying worktop, and cheese samples. Adaptation of individual production processes to inhibit Staph. aureus growth and enterotoxin formation (Cretenet et al., 2011; Johler et al., 2016) could reduce the risk of infection for the consumer.

Our findings show that enterotoxigenic Staph. aureus strains are very common all along the artisan raw milk cheese production process. As staphylococcal food poisoning outbreaks linked to raw milk cheeses and artisanal cheeses have been reported, the presented data on the occurrence and enterotoxigenicity of these strains are crucial to improve risk assessment and to determine the spread and distribution of isolates. It is particularly alarming that $80 \%$ of the samples taken from the final product were positive for Staph. aureus.
As these cheeses are predominantly intended for direct consumption, the high prevalence of Staph. aureus in artisan raw milk cheeses raises concern for human health. Stringent control measures are needed to inhibit growth and enterotoxin formation of Staph. aureus and to prevent staphylococcal food poisoning.

\section{ACKNOWLEDGMENTS}

This research was funded by Italian Ministry of Health (IMH) in the form of a research grant (R.C. 2009-IZSPLV Grant Number 11/09). Research in the Decastelli laboratory is also funded by IMH for the "National Reference Laboratory for Coagulase Positive Staphylococci, including S. aureus," via Bologna, 148, Torino, Italy. 
Table 3. Overview of typing data and genotypes detected ${ }^{1}$

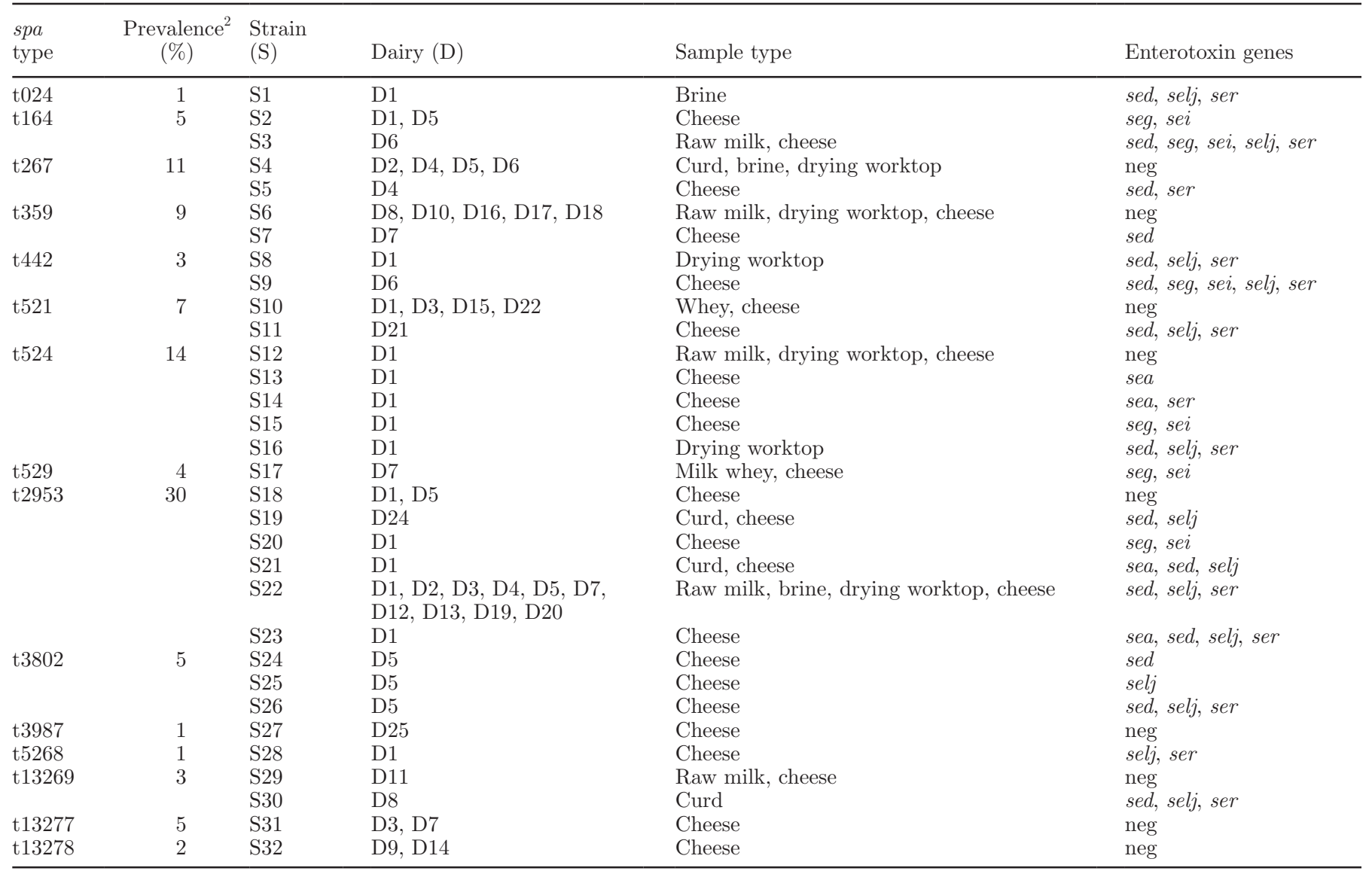

${ }^{1}$ None of the tested isolates harbored $m e c A / m e c C$ genes characteristic of methicillin-resistant Staphylococcus aureus or the pvl gene encoding Panton-Valentine leukocidin. neg $=$ negative.

${ }^{2}$ Proportion of detected Staphylococcus aureus strains positive for the respective spa type.

\section{REFERENCES}

Bania, J., A. Dabrowska, K. Korzekwa, A. Zarczynska, J. Bystron, J. Chrzanowska, and J. Molenda. 2006. The profiles of enterotoxin genes in Staphylococcus aureus from nasal carriers. Lett. Appl. Microbiol. 42:315-320.

Bhattacharyya, D., J. Banerjee, S. Bandyopadhyay, B. Mondal, P. K. Nanda, I. Samanta, A. Mahanti, A. K. Das, G. Das, P. Dandapat, and S. Bandyopadhyay. 2016. First report on vancomycin-resistant Staphylococcus aureus in bovine and caprine milk. Microb. Drug Resist. 22:675-681.

Bianchi, D. M., S. Gallina, A. Bellio, F. Chiesa, T. Civera, and L. Decastelli. 2014. Enterotoxin gene profiles of Staphylococcus aureus isolated from milk and dairy products in Italy. Lett. Appl. Microbiol. 58:190-196.

Blaiotta, G., V. Fusco, C. Von Eiff, F. Villani, and K. Becker. 2006. Biotyping of enterotoxigenic Staphylococcus aureus by enterotoxin gene cluster (egc) polymorphism and spa typing analyses. Appl. Environ. Microbiol. 72:6117-6123.

Boss, R., A. Cosandey, M. Luini, K. Artursson, M. Bardiau, F. Breitenwieser, E. Hehenberger, T. Lam, M. Mansfeld, A. Michel, G. Mösslacher, J. Naskova, S. Nelson, O. Podpečan, A. Raemy, E. Ryan, O. Salat, P. Zangerl, A. Steiner, and H. U. Graber. 2016. Bovine Staphylococcus aureus: Subtyping, evolution, and zoonotic transfer. J. Dairy Sci. 99:515-528.

Chiang, Y. C., W. W. Liao, C. M. Fan, W. Y. Pai, C. S. Chiou, and H. Y. Tsen. 2008. PCR detection of staphylococcal enterotoxins
(SEs) N, O, P, Q, R, U, and survey of SE types in Staphylococcus aureus isolates from food-poisoning cases in Taiwan. Int. J. Food Microbiol. 121:66-73

Cretenet, M., S. Even, and Y. Loir. 2011. Unveiling Staphylococcus aureus enterotoxin production in dairy products: A review of recent advances to face new challenges. Dairy Sci. Technol. 91:127-150.

D'amico, D., and C. Donnelly. 2011. Characterization of Staphylococcus aureus strains isolated from raw milk utilized in small-scale artisan cheese production. J. Food Prot. 74:1353-1358.

Graber, H. U., J. Naskova, E. Studer, T. Kaufmann, M. Kirchhofer, M. Brechbühl, W. Schaeren, A. Steiner, and C. Fournier. 2009. Mastitis-related subtypes of bovine Staphylococcus aureus are characterized by different clinical properties. J. Dairy Sci. 92:1442-1451.

Hasman, H., A. Moodley, L. Guardabassi, M. Stegger, R. L. Skov, and F. M. Aarestrup. 2010. Spa type distribution in Staphylococcus aureus originating from pigs, cattle and poultry. Vet. Microbiol. 141:326-331.

Herrera, F. C., M.-L. García-López, and J. A. Santos. 2016. Short communication: Characterization of methicillin-resistant Staphylococcus aureus isolated from raw milk fresh cheese in Colombia. J. Dairy Sci. 99:7872-7876.

Hummerjohann, J., J. Naskova, A. Baumgartner, and H. U. Graber. 2014. Enterotoxin-producing Staphylococcus aureus genotype B as a major contaminant in Swiss raw milk cheese. J. Dairy Sci. 97:1305-1312.

ISO. 1999. 6888-2. Microbiology of food and animal feeding stuffsHorizontal method for the enumeration of coagulase positive 
staphylococci (S. aureus and other species): Part 2. Technique using rabbit plasma fibrinogen agar medium, International Organization of Standardization (ISO), Geneva, Switzerland.

Johler, S., P. Giannini, M. Jermini, J. Hummerjohann, A. Baumgartner, and R. Stephan. 2015a. Further evidence for staphylococcal food poisoning outbreaks caused by egc-encoded enterotoxins. Toxins (Basel) 7:997-1004.

Johler, S., F. Layer, and R. Stephan. 2011. Comparison of virulence and antibiotic resistance genes of food poisoning outbreak isolates of Staphylococcus aureus with isolates obtained from bovine mastitis milk and pig carcasses. J. Food Prot. 74:1852-1859.

Johler, S., C. Weder, M.-C. Bridy, L. Huguenin, J. Robert, Hummerjohann, and R. Stephan. 2015b. Outbreak of staphylococcal food poisoning among children and staff at a Swiss boarding school due to soft cheese made from raw milk. J. Dairy Sci. 98:2944-2948.

Johler, S., K. Zurfluh, and R. Stephan. 2016. Tracing and growth inhibition of Staphylococcus aureus in barbecue cheese production after product recall. J. Dairy Sci. 99:3345-3350.

Kérouanton, A., J. A. Hennekinne, C. Letertre, L. Petit, O. Chesneau, A. Brisabois, and M. L. De Buyser. 2007. Characterization of Staphylococcus aureus strains associated with food poisoning outbreaks in France. Int. J. Food Microbiol. 115:369-375.

Koreen, L., S. V. Ramaswamy, E. A. Graviss, S. Naidich, J. M. Musser, and B. N. Kreiswirth. 2004. Spa typing method for discriminating among Staphylococcus aureus isolates: Implications for use of a single marker to detect genetic micro- and macrovariation. J. Clin. Microbiol. 42:792-799.

Krupa, P., J. Bystroń, J. Bania, M. Podkowik, J. Empel, and A. Mroczkowska. 2014. Genotypes and oxacillin resistance of Staphylococcus aureus from chicken and chicken meat in Poland. Poult. Sci. 93:3179-3186.

Mancini, F., M. Monaco, M. G. Basanisi, G. La Salandra, and A Pantosti. 2015. An unusual PVL-positive MRSA strain in milk and dairy products from a region of South Italy. J. Glob. Antimicrob. Resist. 3:151-152.
Mehrotra, M., G. Wang, and W. M. Johnson. 2000. Multiplex PCR for detection of genes for Staphylococcus aureus enterotoxins, exfoliative toxins, toxic shock syndrome toxin 1 , and methicillin resistance. J. Clin. Microbiol. 38:1032-1035.

Merz, A., R. Stephan, and S. Johler. 2016. Staphylococcus aureus isolates from goat and sheep milk seem to be closely related and differ from isolates detected from bovine milk. Front. Microbiol. 7:319.

Nulens, E., E. E. Stobberingh, H. van Dessel, S. Sebastian, F. H. van Tiel, P. S. Beisser, and R. H. Deurenberg. 2008. Molecular characterization of Staphylococcus aureus bloodstream isolates collected in a Dutch University Hospital between 1999 and 2006. J. Clin. Microbiol. 46:2438-2441.

Parisi, A., M. Caruso, G. Normanno, L. Latorre, R. Sottili, A. Miccolupo, R. Fraccalvieri, and G. Santagada. 2016. Prevalence, antimicrobial susceptibility and molecular typing of methicillin-resistant Staphylococcus aureus (MRSA) in bulk tank milk from southern Italy. Food Microbiol. 58:36-42.

Sakwinska, O., D. Morisset, J.-Y. Madec, A. Waldvogel, P. Moreillon, and M. Haenni. 2011. Link between genotype and antimicrobial resistance in bovine mastitis-related Staphylococcus aureus strains, determined by comparing Swiss and French isolates from the Rhône Valley. Appl. Environ. Microbiol. 77:3428-3432.

Sharma, N. K., C. E. Rees, and C. E. Dodd. 2000. Development of a single-reaction multiplex PCR toxin typing assay for Staphylococcus aureus strains. Appl. Environ. Microbiol. 66:1347-1353.

Spanu, V., C. Spanu, S. Virdis, F. Cossu, C. Scarano, and E. P. L. De Santis. 2012. Virulence factors and genetic variability of Staphylococcus aureus strains isolated from raw sheep's milk cheese. Int. J. Food Microbiol. 153:53-57.

Stegger, M., P. S. Andersen, A. Kearns, B. Pichon, M. A. Holmes, G. Edwards, F. Laurent, C. Teale, R. Skov, and A. R. Larsen. 2012. Rapid detection, differentiation and typing of methicillin-resistant Staphylococcus aureus harbouring either mecA or the new mecA homologue mecA LGA251. Clin. Microbiol. Infect. 18:395-400. 